\title{
La Motte-en-Bauges
}

Les Dalphins

\section{Pascale Réthoré}

\section{(2) OpenEdition}

\section{Journals}

Édition électronique

URL : http://journals.openedition.org/adlfi/6996

ISSN : 2114-0502

Éditeur

Ministère de la culture

Référence électronique

Pascale Réthoré, "La Motte-en-Bauges », ADLFI. Archéologie de la France - Informations [En ligne] Rhône-Alpes, mis en ligne le 01 mars 2007, consulté le 19 avril 2019. URL : http:// journals.openedition.org/adlfi/6996

Ce document a été généré automatiquement le 19 avril 2019

(C) Ministère de la Culture et de la Communication, CNRS 


\title{
La Motte-en-Bauges
}

\author{
Les Dalphins
}

\section{Pascale Réthoré}

Identifiant de l'opération archéologique : 229321

Date de l'opération : 2007 (EX)

1 L'objectif de ce diagnostic était de vérifier l'extension des vestiges d'un ensemble de bâtiments antiques reconnus notamment en 2005 au cours du diagnostic de la parcelle voisine. Deux bâtiments avaient été identifiés. Le plan du bâtiment sud constitué d'au moins deux pièces a pu être complété. Ce plan demeure cependant incomplet, faute de temps pour élargir les investigations. L'emprise globale du bâti est d'au moins $140 \mathrm{~m}^{2}$.

Deux périodes d'occupation au moins ont été individualisées : la première implantation remonte au Haut-Empire. À la suite d'un incendie, le bâtiment est reconstruit et utilisé au cours des $\mathrm{II}^{\mathrm{e}} \mathrm{s}$. et $\mathrm{III}^{\mathrm{e}} \mathrm{s}$. Sa fonction reste inconnue; il ne possède aucun sol construit dans sa partie étudiée et la stratigraphie est succinte.

3 La présence de nombreux clous de tout type, recueillis dans les niveaux des II $^{\mathrm{e}} \mathrm{s}$. et III $\mathrm{s}$. présente une particularité. En effet, il ne s'agit pas seulement de clous de charpente habituellement présents dans les niveaux de destruction, mais aussi de clous de plus petits modules associés à quelques scories. Ces éléments pourraient orienter vers l'interprétation d'un bâtiment à vocation artisanale, tourné vers la production de ce type d'objets.

4 En effet, la clouterie est l'une des principales activités artisanales pré-industrielles du massif des Bauges au cours des Temps Modernes et une exploitation dès l'Antiquité des gisements métallifères est hautement probable. Cela reste toutefois une simple proposition d'interprétation, faute d'éléments tout à fait probants.

5 RÉTHORÉ Pascale 
INDEX

Index chronologique : Antiquité romaine, Empire romain, Haut-Empire, IIe siècle apr. J.-C., IIIe siècle apr. J.-C.

operation Expertise (EX)

Index géographique : Rhône-Alpes, Savoie (73), Motte-en-Bauges

\section{AUTEURS}

\section{PASCALE RÉTHORÉ}

INRAP 